\title{
Protective role of the half-center oscillator connectivity against external perturbations
}

\author{
William Barnett, Aaron Gomez-Lugo, Gennady Cymbalyuk \\ From Twenty Second Annual Computational Neuroscience Meeting: CNS*2013 \\ Paris, France. 13-18 July 2013
}

Central pattern generators (CPGs) are neuronal circuits that control rhythmic movements in animals. The heartbeat of the medicinal leech is controlled by a CPG that is distributed over several ganglia. In ganglia 3 and 4, there are half-center oscillators (HCOs): pairs of reciprocally inhibitory heart interneurons (HNs). These HCOs form the kernel of the heartbeat CPG, and each HCO is composed of a pair of endogenously bursting heart interneurons [1]. A canonical model of the $\mathrm{HN}$ accurately reproduces experimental results [1,2]. It also exhibits bistability of bursting and silence in single $\mathrm{HNs}$ and the $\mathrm{HCO}$ $[1,3]$. The single $\mathrm{HN}$ and $\mathrm{HCO}$ model have been expanded into a family of models that satisfy biological constraints [2]. Multistability is highly prevalent in this database [4]. The coexistence of bursting and silent regimes could present a life threatening condition for the animal. If a perturbation were able to trigger a switch in the activity of the CPG to a silent state, circulation of blood in the leech would be crippled. Our hypothesis is that the $\mathrm{HCO}$ connectivity protects functional pattern of activity against an external perturbation.

Here, we investigated the perturbations that switch the activity of the $\mathrm{HN}$ and the $\mathrm{HCO}$ from bursting to silence. Over a series of simulations, we applied a $30 \mathrm{~ms}$ pulse of current with various amplitudes and phases of application in the period of bursting activity. This protocol provided a set of pulse parameters in the (phase, amplitude) parameter space for which a switch was triggered. In the canonical model of a single $\mathrm{HN}$ for which the leak conductance was $9.59 \mathrm{nS}$, both depolarizing and hyperpolarizing pulses could trigger switches (Figure 1). We observed contiguous sets of pulse parameters where triggered switches occurred, but there were also fine structures in the parameter space (Figure 1). We estimated the susceptibility of bursting activity in the $\mathrm{HN}$ to perturbations by the

\footnotetext{
* Correspondence: gcymbalyuk@gsu.edu

Neuroscience Institute, Georgia State University, Atlanta, Georgia 30303, USA
}

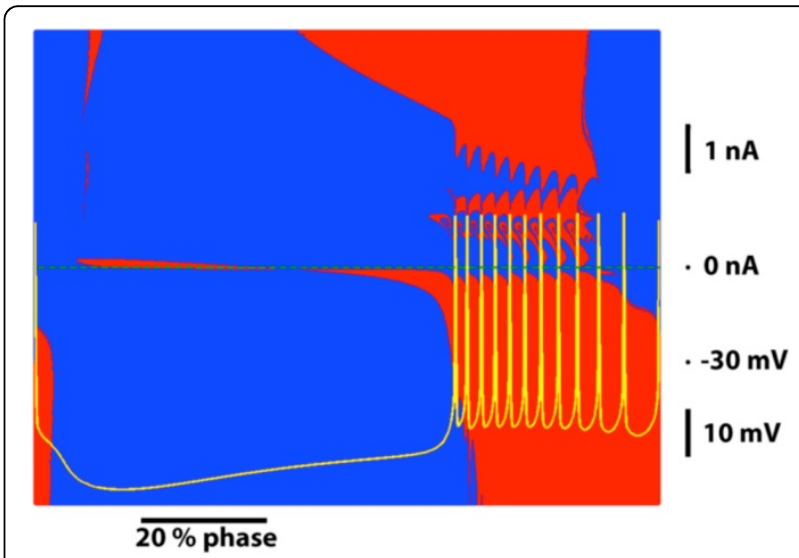

Figure 1 Properties of pulses triggering a switch from bursting to silence. Red or blue points indicate a switch or failure to switch. The yellow trajectory is the bursting waveform that defines the phase. The green dashed line indicates $0 \mathrm{nA}$.

proportion of pulse parameter sets that would trigger a switch to the total number of trials. We found that $20.84 \%$ of pulses triggered a switch (Figure 1). We repeated this pulse protocol in the $\mathrm{HCO}$ for the same parameter values of the ionic conductances, and found that no pulses elicited a switch from bursting to silence. Our results suggest that in a network consisting of bistable elements, the halfcenter oscillator connectivity protects the functional regime against external perturbations.

\section{Acknowledgements}

The authors acknowledge support from NSF grant PHY-0750456.

Published: 8 July 2013

\section{References}

1. Cymbalyuk GS, Gaudry Q, Masino MA, Calabrese RL: Bursting in leech heart interneurons: cell-autonomous and network-based mechanisms. J Neurosci 2002, 22:10580-10592. 
2. Doloc-Mihu A, Calabrese RL: A database of computational models of a half-center oscillator for analyzing how neuronal parameters influence network activity. J Biol Phys 2011, 37:263-283.

3. Malashchenko T, Shilnikov A, Cymbalyuk G: Bistability of bursting and silence regimes in a model of a leech heart interneuron. Phys Rev E Stat Nonlin Soft Matter Phys 2011, 84:041910.

4. Marin B, Barnett W, Doloc-Mihu A, Calabrese R, Cymbalyuk G: High prevalence of multistability of rest states and bursting in a database of a model neuron. PLoS Comput Biol 2013, 9(3):e1002930.

doi:10.1186/1471-2202-14-S1-P77

Cite this article as: Barnett et al:: Protective role of the half-center oscillator connectivity against external perturbations. BMC Neuroscience 2013 14(Suppl 1):P77.

\section{Submit your next manuscript to BioMed Central} and take full advantage of:

- Convenient online submission

- Thorough peer review

- No space constraints or color figure charges

- Immediate publication on acceptance

- Inclusion in PubMed, CAS, Scopus and Google Scholar

- Research which is freely available for redistribution

Submit your manuscript at www.biomedcentral.com/submit 